\title{
Evidence of eutectic crystallization and transient nucleation in Al89La6Ni5 amorphous alloy
}

Zhuang, Yanxin; Jiang, Jianzhong; Lin, Z. G.; Mezouar, M.; Crichton, W.; Inoue, A.

Published in:

Applied Physics Letters

Link to article, DOI:

$10.1063 / 1.1389506$

Publication date:

2001

Document Version

Publisher's PDF, also known as Version of record

Link back to DTU Orbit

Citation (APA):

Zhuang, Y., Jiang, J., Lin, Z. G., Mezouar, M., Crichton, W., \& Inoue, A. (2001). Evidence of eutectic crystallization and transient nucleation in Al89La6Ni5 amorphous alloy. Applied Physics Letters, 79(6), 743-745. https://doi.org/10.1063/1.1389506

\section{General rights}

Copyright and moral rights for the publications made accessible in the public portal are retained by the authors and/or other copyright owners and it is a condition of accessing publications that users recognise and abide by the legal requirements associated with these rights.

- Users may download and print one copy of any publication from the public portal for the purpose of private study or research.

- You may not further distribute the material or use it for any profit-making activity or commercial gain

- You may freely distribute the URL identifying the publication in the public portal 


\title{
Evidence of eutectic crystallization and transient nucleation in $\mathrm{Al}_{89} \mathrm{La}_{6} \mathrm{Ni}_{5}$ amorphous alloy
}

\author{
Y. X. Zhuang, J. Z. Jiang, ${ }^{\text {a) }}$ and Z. G. Lin \\ Department of Physics, Building 307, Technical University of Denmark, DK-2800 Lyngby, Denmark \\ M. Mezouar and W. Crichton \\ European Synchrotron Radiation Facility (ESRF), BP 220, 38000 Grenoble, France
}

A. Inoue

Institute of Materials Research, Tohoku University, Sendai 980-77, Japan

(Received 21 August 2000; accepted for publication 1 June 2001)

\begin{abstract}
The phase evolution with the temperature and time in the process of crystallization of $\mathrm{Al}_{89} \mathrm{La}_{6} \mathrm{Ni}_{5}$ amorphous alloy has been investigated by in situ high-temperature and high-pressure x-ray powder diffraction using synchrotron radiation. Two crystalline phases, fcc-Al and a metastable bcc$(\mathrm{AlNi})_{11} \mathrm{La}_{3}$-like phase, were identified after the first crystallization reaction, revealing a eutectic reaction instead of a primary reaction suggested in the literature. Time-dependent nucleation in the amorphous alloy is detected and the experimental data can be fitted by both the Zeldovich's and Kashchiev's transient nucleation models with transient nucleation times of 220 and 120 min, respectively. (C) 2001 American Institute of Physics. [DOI: 10.1063/1.1389506]
\end{abstract}

Al-based amorphous alloys with an Al concentration of about 90 at \% have attracted much attention due to their mechanical properties, especially the high strength combined with a good ductility which is much superior to that of conventional high-strength aluminum alloys. ${ }^{1,2}$ The mechanical properties of partially crystallized amorphous alloys with nanometer-sized $\mathrm{Al}$ crystals could be even enhanced. ${ }^{3-5}$ These excellent mechanical properties make this family of Al-based amorphous alloys promising candidates as advanced engineering materials. The precipitation of facecentered-cubic (fcc)-Al nanocrystals from the amorphous alloys is generally assumed to be a primary reaction with longrange atomic diffusion, while Chen et al. ${ }^{6}$ suggested that the local atomic rearrangement instead of the long-range atomic diffusion is responsible for the formation of $\mathrm{Al}$ nanocrystals during deformation. Ye and $\mathrm{Lu}^{7}$ reported the formation of single fcc-Al phase after the first primary crystallization in an $\mathrm{Al}_{89} \mathrm{La}_{6} \mathrm{Ni}_{5}$ amorphous alloy. On the other hand, Gogebakan et al. ${ }^{8}$ observed that the crystalline phases after the first crystallization reaction in an $\mathrm{Al}_{85} \mathrm{Y}_{11} \mathrm{Ni}_{4}$ alloy are fcc-Al, $\mathrm{Al}_{3} \mathrm{Y}$, and some unidentified metastable intermetallic phases, indicating a eutectic reaction. Gangopadhyay and Kelton ${ }^{9}$ further investigated the crystallization processes and found that the crystallization products depend on the radius of rareearth atoms. The x-ray powder diffraction pattern (XRD) recorded after the first crystallization reaction in an $\mathrm{Al}_{88} \mathrm{La}_{8} \mathrm{Ni}_{4}$ alloy shows two crystalline phases, although the authors did not clarify the point in their work. ${ }^{9}$ In this work, we present experimental evidence of the eutectic crystallization reaction and transient nucleation in the $\mathrm{Al}_{89} \mathrm{La}_{6} \mathrm{Ni}_{5}$ amorphous alloy by means of in situ high-temperature (293-673 K) and highpressure (0-4 GPa) angle-dispersive XRD measurements using synchrotron radiation. Two crystalline phases, fcc-Al and

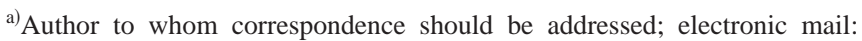
jiang@fysik.dtu.dk
}

a metastable body-centered-cubic (bcc)-(AlNi) ${ }_{11} \mathrm{La}_{3}$-like phase, were identified after the first crystallization reaction. Time-dependent nucleation is observed in the amorphous alloy during the crystallization kinetic process and successfully described by classic transient nucleation theory.

Ingots, with nominal composition $\mathrm{Al}_{89} \mathrm{La}_{6} \mathrm{Ni}_{5}$, were prepared by arc melting a mixture of pure $\mathrm{Al}(99.99 \mathrm{wt} \%)$, La, (99.9 wt \%), and $\mathrm{Ni}$ (above $99.96 \mathrm{wt} \%$ ) in a purified argon atmosphere. Details of sample preparation and characterization were reported in Ref. 10. Differential scanning calorimetry (DSC) measurements were performed in a flowing purified argon atmosphere using a Perkin-Elmer DSC-7 at a heating rate of $40 \mathrm{~K} / \mathrm{min}$. The amorphous alloy exhibits two exothermic crystallization reactions with the onset temperatures $T_{x 1}$ and $T_{x 2}$ of $494.1 \mathrm{~K}$ and $611.9 \mathrm{~K}$, respectively. In situ high-pressure and high-temperature angle-dispersive XRD measurements were performed by synchrotron radiation using the Paris-Edinburgh large-volume apparatus available at European Synchrotron Radiation Facility (ESRF) in Grenoble, France with a wavelength of 0.20215 $\AA .{ }^{10}$ Instrumental line broadening is negligible. The temperature was measured by means of a K-type thermocouple with a stability of $\pm 1 \mathrm{~K}$. Each run consisted of an isothermal room-temperature compression followed by an isobaric heating to a high temperature in steps of $10 \mathrm{~K}$. The average heating rate in the temperature range from 298 to $673 \mathrm{~K}$ was roughly estimated to be $3 \mathrm{~K} / \mathrm{min}$. The kinetic XRD patterns were recorded for each $10 \mathrm{~min}$ at a given temperature and pressure, in which the temperature is rapidly heated to the given one without overshoot. The pressure of the sample is calculated from the equation of state of BN. ${ }^{11}$

Figure 1 exemplifies XRD patterns recorded at $2 \mathrm{GPa}$ and various temperatures. A broad amorphous peak, located at $2 \theta \approx 4.8^{\circ}$, together with Bragg peaks from BN marked in Fig. 1 and from the gasket in the $2 \theta$ range of $2-3^{\circ}$ are observed in the XRD patterns recorded at 298, 373, and $483 \mathrm{~K}$. 


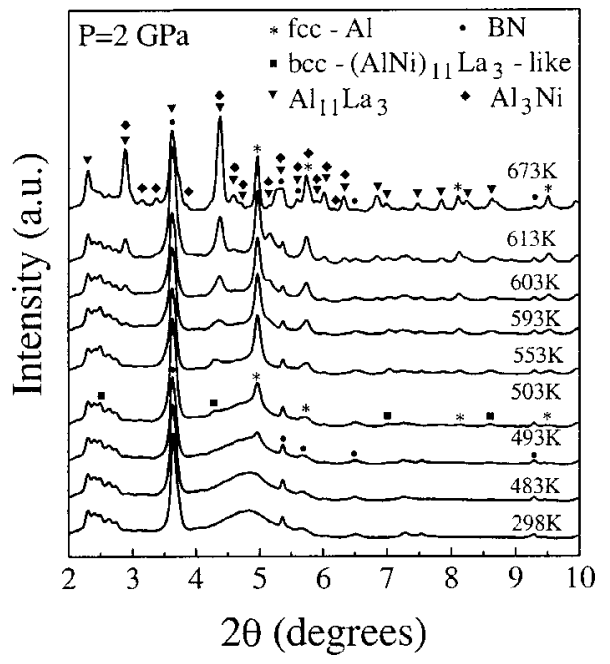

FIG. 1. In situ high-temperature and high-pressure XRD patterns recorded at various temperatures for the $\mathrm{Al}_{89} \mathrm{La}_{6} \mathrm{Ni}_{5}$ amorphous alloy are shown.

It is seen that a new tiny crystalline peak $\left(2 \theta \approx 5^{\circ}\right)$ appears at $493 \mathrm{~K}$ together with four new Bragg peaks located at $2 \theta$ $\approx 2.47^{\circ}, 4.26^{\circ}, 6.98^{\circ}$, and $8.59^{\circ}$. The four new Bragg peaks can be indexed to a bcc structure with a lattice constant of $6.64 \AA$ and space group $\operatorname{Im} 3 \mathrm{~m}$. The observed and calculated interplanar spacings of the cubic phase together with the data from Ref. 9 are listed in Table I. These Bragg peaks are very close to the corresponding peaks for the orthorhombic $\mathrm{Al}_{11} \mathrm{La}_{3}$ phase. The atomic radius of $\mathrm{Ni}$ is close to that of $\mathrm{Al}$. Thus, it is not unreasonable to suggest that the new cubic phase could be a bcc-(AlNi) ${ }_{11} \mathrm{La}_{3}$-like phase. This cubic phase together with the fcc-Al phase are observed in all XRD patterns recorded after the first crystallization process at various pressures. These results indicate that the first crystallization process of the $\mathrm{Al}_{89} \mathrm{La}_{6} \mathrm{Ni}_{5}$ amorphous alloy is governed by a eutectic reaction rather than a primary reaction, which was suggested in the literature. ${ }^{7}$ With increasing temperature, the crystalline peaks become narrower in width and higher in intensity. More Bragg peaks appear in the XRD pattern recorded at $603 \mathrm{~K}$, indicating that the residual amorphous phase begins to crystallize and the bcc $(\mathrm{AlNi})_{11} \mathrm{La}_{3}$-like phase starts to decompose. At $673 \mathrm{~K}$, fcc- $\mathrm{Al}, \mathrm{Al}_{11} \mathrm{La}_{3}$, and $\mathrm{Al}_{3} \mathrm{Ni}$, together with a few tiny peaks, are detected while the bcc $(\mathrm{AlNi})_{11} \mathrm{La}_{3}$-like phase disappears.

To further study the first crystallization reaction in the $\mathrm{Al}_{89} \mathrm{La}_{6} \mathrm{Ni}_{5}$ amorphous alloy, in situ high-temperature kinetic $\mathrm{XRD}$ measurements were performed, as shown in Fig. 2. It is

TABLE I. Interplanar spacings of the metastable bcc-AlNi ${ }_{11} \mathrm{La}_{3}$-like phase with a lattice constant of $6.64 \AA$ and space group Im3m obtained from the in situ XRD pattern recorded at $503 \mathrm{~K}$ and $2 \mathrm{GPa}$ for the $\mathrm{Al}_{89} \mathrm{La}_{6} \mathrm{Ni}_{5}$ amorphous alloy are shown. The data obtained from Ref. 9 are at ambient temperature and pressure.

\begin{tabular}{llcc}
\hline \hline$h k l$ & $d_{\text {cal }}(\AA)$ & $d_{\exp }(\AA)$ & $d_{\exp }(\AA)^{\mathrm{b}}$ \\
\hline 110 & 4.695 & 4.69 & 4.67 \\
200 & $3.32^{\mathrm{a}}$ & & 3.30 \\
211 & 2.711 & 2.72 & 2.70 \\
220 & $2.348^{\mathrm{a}}$ & & 2.34 \\
400 & 1.66 & 1.66 & 1.64 \\
422 & 1.355 & 1.35 & 1.34 \\
\hline \hline
\end{tabular}

${ }^{a}$ Peaks are overlapped with those of $\mathrm{BN}$ or fcc Al.

bData are from Ref. 9.

Downloaded 24 Feb 2010 to 192.38.67.112. Redistribution subject to AlP license or copyright; see http://apl.aip.org/apl/copyright.jsp

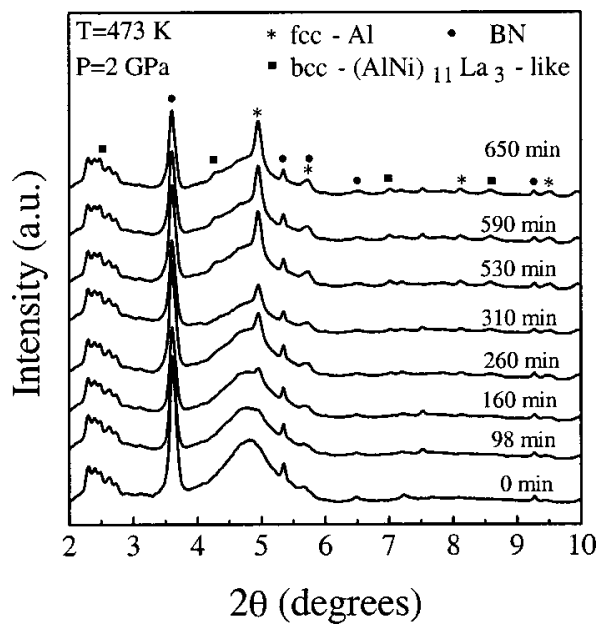

FIG. 2. In situ kinetic XRD patterns recorded at $473 \mathrm{~K}$ and $2 \mathrm{GPa}$ as a function of time for the $\mathrm{Al}_{89} \mathrm{La}_{6} \mathrm{Ni}_{5}$ amorphous alloy are shown.

found that the first crystalline phases formed are fcc- $\mathrm{Al}$ and the metastable bcc-(AlNi) ${ }_{11} \mathrm{La}_{3}$-like phase. This result confirms that the first crystallization reaction in the $\mathrm{Al}_{89} \mathrm{La}_{6} \mathrm{Ni}_{5}$ amorphous alloy is a eutectic rather than a primary reaction.

During the crystallization process, the relative volume fraction, $f$, of the crystalline component at a given time, $t$, is estimated from the expression: $Y(t)=(1-f) Y(0)$ $+f Y\left(t_{\max }\right)$, where $Y(t), Y(0)$, and $Y\left(t_{\max }\right)$ are the XRD patterns at times of $t, 0, t_{\max }$, respectively. $t_{\max }$ is randomly selected. Figure 3 shows the relative volume fraction as a function of time together with three theoretical fitting curves (details given later). From transmission electron microscopy measurements, it was found that during the first crystallization reaction of the amorphous alloy, the crystals rapidly grow and then saturate to a value of around 15-20 nm. It was also found in Fig. 2 that the widths of Bragg peaks remain almost constant while the instrumental line broadening is negligible. These results infer that the relative volume fraction might be proportional to the relative number of nucleation with a constant crystal size. Six possible nucleation and growth models were applied to fit the data in Fig. 3 . They are (1) model 1: heterogeneous nucleation with constant growth rate, (2) model 2: steady-state nucleation with constant growth rate, (3) model 3: time-dependent Kashchiev's nucleation ${ }^{12}$ with constant growth rate, (4) model 4 : heterogeneous nucleation with zero growth rate (i.e., constant grain size), (5) model 5: steady-state nucleation with zero growth rate, and (6) model 6: time-dependent Kashchiev's nucleation with zero growth rate. It was found that models 3, 4, and 5 can not fit the data at all. Figure 3 shows fitting results using models 1,2 , and 6 . It is clearly seen that the best fit was obtained using the model 6 with a transient time of $120 \mathrm{~min}$. Due to fast nucleation processes in amorphous alloys, steady-state nucleation has been considered in most cases. Very few comprehensive experimental investigations of time-dependent nucleation in metallic glasses have been reported. ${ }^{13,14}$ In the classic transient nucleation theory, two analyses, based on the Zeldovich-Frenkel equation, ${ }^{15}$ were proposed. One is the Zeldovich's equation. Zeldovich ${ }^{15}$ assumed that the work of formation of a nucleus with size of $n$ is proportional to $n^{2}$ and the rate of monomer addition to a nucleus with size of $n, k_{n}^{+} \approx k_{n *}^{+}$, and found a time- 


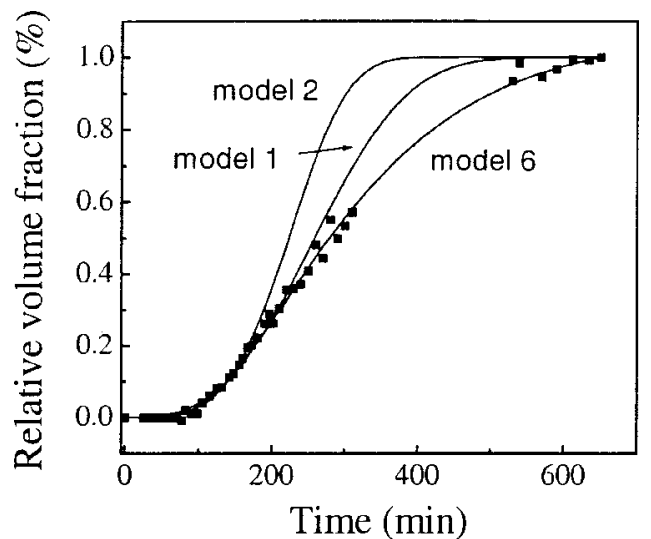

FIG. 3. Relative volume fraction of the crystalline component with time during the isothermal annealing at $473 \mathrm{~K}$ and $2 \mathrm{GPa}$ for the $\mathrm{Al}_{89} \mathrm{La}_{6} \mathrm{Ni}_{5}$ amorphous alloy, having $t_{\max }=650 \mathrm{~min}$ is shown. In the time period of about 310-510 min. synchrotron radiation $\mathrm{x}$-ray beam was lost in the storage ring during the measurement.

dependent nucleation rate, $I_{n *}(t)$, at the critical size $n^{*}$ as:

$$
I_{n *}=I_{\mathrm{st}} \exp \left(-\tau_{z} / t\right)
$$

where $\tau_{z}$ is the transient nucleation time, $\tau_{z}$ $=\left(256 \pi \sigma^{6} v^{4}\right) /\left(9 \delta \mu^{6} k_{n *}^{+}\right), \delta \mu$ is the difference of the Gibbs free energies per molecule between the crystalline and amorphous phases, $\sigma$ is the interfacial energy per unit area, and $v$ is the molecular volume. The other is the Kashchiev's equation. ${ }^{12}$ Kashchiev further studied the transient nucleation process and performed the most thorough analytical treatment of the Zeldovich-Frenkel equation. Based on two assumptions: (1) the work of the formation of a nucleus with size of $n$ is approximated by the first two nonzero terms in a Taylor expansion about $n^{*}$, and (2) $k_{n}^{+} \approx k_{n^{*}}^{+}$, he derived the time-dependent nucleation rate as:

$$
I_{n *}=I_{\mathrm{st}}\left[1+2 \sum_{m=1}^{\infty}(-1)^{m} \exp \left(-\frac{m^{2} t}{\tau_{K}}\right)\right],
$$

where $\tau_{K}$ is the transient nucleation time, $\tau_{K}$ $=\left(256 k_{B} T \sigma^{3} v^{2}\right) /\left(\pi \delta \mu^{4} k_{n *}^{+}\right), k_{B}$ is the Boltzmann's constant, and $T$ is the temperature. The ratio of the transient nucleation times in both models is given by $\tau_{Z} / \tau_{K}$ $=\left(\pi^{3} \sigma^{3} v^{2}\right) /\left(9 k_{B} T \delta \mu^{2}\right)$. Both transient nucleation models can well fit the data in Fig. 3 with $\tau_{Z}=220 \mathrm{~min}$ and $\tau_{K}$ $=120 \mathrm{~min}$. The induction time, $\theta$, defined by the extrapolation of the steady-state nucleation behavior to the time axis, and the steady-state time, $t_{\mathrm{st}}$, at which the nucleation rate is time independent, ${ }^{16}$ are estimated to be $\theta=116 \mathrm{~min}$ and $t_{\mathrm{st}}$ $=160 \mathrm{~min}$, respectively, as shown in Fig. 4. The induction time, $\theta$, is most directly related to the transient nucleation time, $\tau{ }^{16}$ It is clear that the transient nucleation time, $\tau_{K}$ $=120 \mathrm{~min}$, derived from the Kashchiev's model, is much closer to the induction time, $\theta=116 \mathrm{~min}$, than $\tau_{Z}=220 \mathrm{~min}$ derived from the Zeldovich's model. For the $\mathrm{Al}_{89} \mathrm{La}_{6} \mathrm{Ni}_{5}$ amorphous alloy, using $\sigma=0.108 \mathrm{~J} / \mathrm{m}^{2}$ for the liquid-solid interfacial energy of aluminum, ${ }^{16}$ molar volume of about 10 $\mathrm{cm}^{3} / \mathrm{mol}$ for the fcc $\mathrm{Al}$ and $T=473 \mathrm{~K}$, the Gibbs free energy

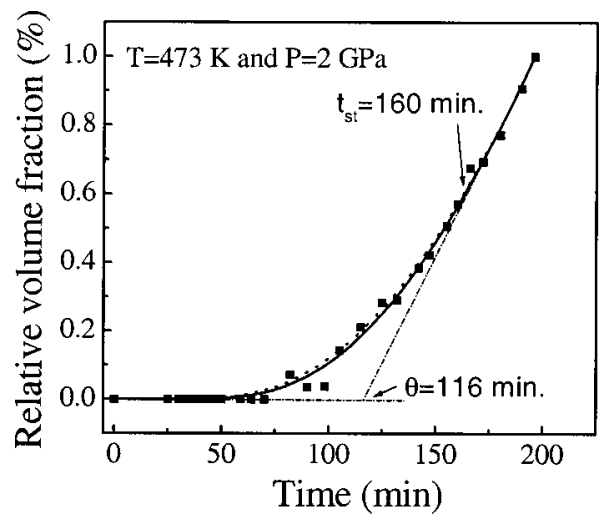

FIG. 4. Relative volume fraction of the crystalline component with time during the isothermal annealing at $473 \mathrm{~K}$ and $2 \mathrm{GPa}$ for the $\mathrm{Al}_{89} \mathrm{La}_{6} \mathrm{Ni}_{5}$ amorphous alloy, having $t_{\max }=196 \mathrm{~min}$ is shown. The induction time, $\theta$, and the steady-state time, $t_{\mathrm{st}}$, are estimated to be $116 \mathrm{~min}$ and $160 \mathrm{~min}$, respectively. The solid and dashed curves are the Zeldovich's and Kashchiev's transient nucleation rate equations with $\tau_{Z}=220 \mathrm{~min}$ and $\tau_{K}=120 \mathrm{~min}$, respectively.

difference per molar between the crystalline and amorphous phases is estimated to be about $602 \mathrm{~J} / \mathrm{cm}^{3}$ at $473 \mathrm{~K}$ and 2 GPa.

In summary, the phase evolution with the temperature and time in the crystallization processes of $\mathrm{Al}_{89} \mathrm{La}_{6} \mathrm{Ni}_{5}$ amorphous alloy has been investigated by in situ high-temperature and high-pressure XRD using synchrotron radiation. It is found that the first crystallization process is a eutectic reaction with two crystalline phases, fcc $\mathrm{Al}$ and the metastable bcc-(AlNi $)_{11} \mathrm{La}_{3}$-like phase. The experimental data, the relative volume fraction of the crystalline component as a function of time, can be described by both the Zeldovich's and Kashchiev's transient nucleation models. The Gibbs free energy difference per molar between the crystalline and amorphous phases is estimated to be about $602 \mathrm{~J} / \mathrm{cm}^{3}$ at $473 \mathrm{~K}$ and $2 \mathrm{GPa}$.

${ }^{1}$ A. Inoue, K. Ohtera, A. P. Tsai, and T. Masumoto, Jpn. J. Appl. Phys., Part 2 27, L280 (1988).

${ }^{2}$ Y. He, S. J. Poon, and G. J. Shiflet, Science 241, 1640 (1988).

${ }^{3}$ H. Chen, Y. He, G. J. Shiflet, and S. J. Poon, Scr. Metall. Mater. 25, 1421 (1991).

${ }^{4}$ A. Inoue, Prog. Mater. Sci. 43, 365 (1998).

${ }^{5}$ T. Gloriant and A. L. Greer, Nanostruct. Mater. 10, 389 (1998).

${ }^{6}$ H. Chen, Y. He, G. J. Shiflet, and S. J. Poon, Nature (London) 367, 541 (1994).

${ }^{7}$ F. Ye and K. Lu, Acta Mater. 47, 2449 (1999); Phys. Rev. B 60, 7018 (1999); J. Non-Cryst. Solids 262, 228 (2000).

${ }^{8}$ M. Gogebakan, P. J. Warren, and B. Cantor, Mater. Sci. Eng., A 226, 168 (1997).

${ }^{9}$ A. K. Gangopadhyay and K. F. Kelton, Philos. Mag. A 80, 1193 (2000).

${ }^{10}$ Y. X. Zhuang, J. Z. Jiang, T. J. Zhou, H. Rasmussen, L. Gerward, M. Mezouar, W. Crichton, and A. Inoue, Appl. Phys. Lett. 77, 4133 (2000).

${ }^{11}$ Y. Le Godec, D. Martinez-Garcia, M. Mezouar, G. Syfosse, J. P. Itie, and J.-M. Besson (unpublished).

${ }^{12}$ D. Kashchiev, Surf. Sci. 14, 209 (1969).

${ }^{13}$ S. Brauer, H. E. Fischer, J. O. Strom-Olsen, M. Sutton, A. Zaluska, and G. B. Stephenson, Phys. Rev. B 47, 11757 (1993).

${ }^{14}$ M. Bushwitz, R. Adlwarth-Dieball, and P. L. Ryder, Acta Metall. Mater. 41, 1885 (1993).

${ }^{15}$ J. B. Zeldovich, Acta Physicochim, URSS 18, 1 (1943); J. I. Frenkel, Kinetic Theory of Liquids (Oxford University Press, London, 1946).

${ }^{16}$ K. F. Kelton, Solid State Phys. 45, 75 (1991). 